\title{
A CONSTITUIÇÃO DO CAMPO DA FILOSOFIA DA EDUCAÇÃO ENTRE OS ANOS 40 A 60
}

\section{Maria Betânia B. ALBUQUERQUE \\ Universidade do Estado do Pará}

Resumo: $O$ artigo resulta de uma investigaçāo em âmbito de dontorado acerca do percurso histórico da disciplina Filosofia da Educação a partir da PUC/SP entre os anos de 1940 a $1990 .{ }^{\prime}$ Especificanente, focaliza a configuração intelectual que teve essa disciplina entre os anos 40 a 60 do século $X X, q u a n d o$ esteve sob a influência da perspectiva tomista. Visa capturar a identidade que a disciplina obteve nesse período a partir dos tenas privilegiados e/ ou silenciados nos programas, dos intelectuais $e$ das obras que serviram de norte ao seu ensino, bem como dos principais eventos que marcaram essa área de conhecimento. O trabalho se insere dentro de um campo de estudos denominado de história das disciplinas acadêmicas que, na sua interface com a Sociologia do Currículo, preocupa-se con a historicidade das disciplinas, seus conflitos internos e externos, seus mentores e obras, entre outros aspectos.

\section{$\Lambda$ rriação da $\mathrm{PUC} / \mathrm{SP}$}

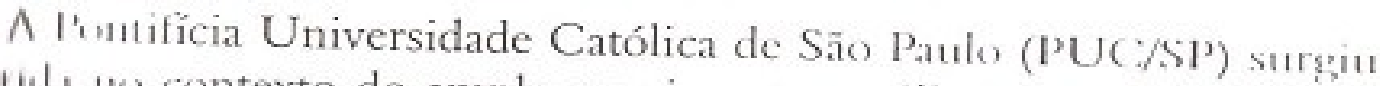

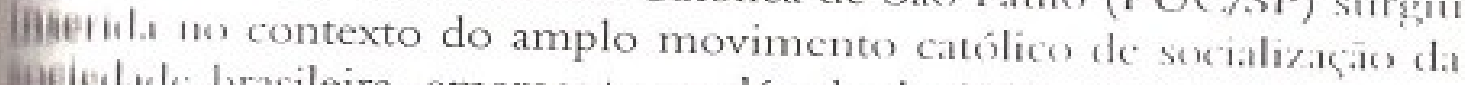
Deleuluk brasileira, emergente na década de 1920, o qual teve, como Iimii ule suas justificativas, a crise de domínio da Igrej. travestida de

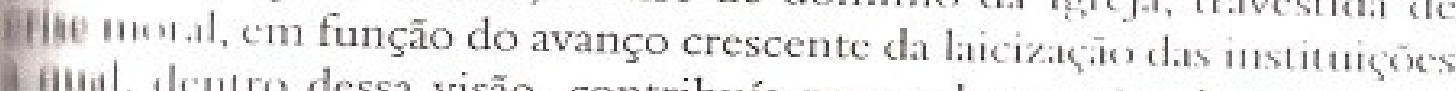
qual, dentro dessa visão, contribuía para solipar a implantacian dos fleân umlicss na sociedade.

1) a corclo com o projeto da Igreja, a veiculašun da espiritualidade alolit teria como meio fundamental o sistema celucacional,

What Hilo, $214 \mathrm{~s}$ : 
especialmente o ensino superior - dimensäo onde se formaria uma clite devidamente aparelhada científica e moralmente para dirigir o país à luz de seus ideais.

O pavor da Igreja Católica diante dos sistemas públicos e estatais de ensino e do surgimento de universidades públicas imbuídas de ideais laicos e democráticos, como a Universidade de São Paulo (USP) e a Universidade do Distrito Federal (UDF), a fez investir pesadamente na criação de sua própria universidade, laboratório privilegiado na fabricação da elite necessária ao país: uma elite fundamentalmente católica.

A criação da universidade católica significou, para a Igreja Católica, uma conquista grandiosa face à difícil situação em que se encontrava na década de 40. Não significou, todavia, uma vitória plena considerandose sua grande pretensão de monopolizar a cultura superior do país. Tratava-se, portanto, de aproveitar todas as possibilidades trazidas pela fundação de sua própria universidade, fazendo dela um espaço no qual poderia implementar seu projeto de conformação ético-religiosa das novas geraçōes. Nesse sentido, a PUC-SP (locus institucional deste estudo) representou um espaço privilegiado de produção, divulgação e circulação do ideário católico consubstanciado na filosofia de São Tomás de Aquino, que se infiltrou na instituição sob diferentes perspectivas, inclusive, e sobretudo, nas disciplinas de caráter filosófico como era o caso da Filosofia da Educaşão.

\section{A filosofia tomista no Brasil}

O pensamento tomista, no Brasil, segundo Campos (1968), concentrou-se, no período compreendido entre a Proclamação da República e a Revolução de 1930, no Rio de Janeiro c em São Paulo. No Rio, ele foi difundido, fundamentalmente, através dos intelectuais católicos reunidos em torno do Centro Dom Vital. Já em São Paulo, concentrou-se, prioritariamente, na PUC, na Faculdade de Direito da Universidade de São Paulo e na Faculdade de Filosofia Nossa Senhora Medianeira.

Na PUC-SP, os principais representantes dessa corrente foram Michel Schooyans, Beda Kruse, José Antônio Tobias, Adolfo Crippa e Leonardo Van Acker, considerado "um dos mais ilustres neotomistas do País" (Campos, 1968, p. 123). No contexto deste estudo, destaca-se o nome de Leonardo Van Acker, sobretudo em função da enorme 
Iullućncia que exerceu, como filósofo da educação e professor catedrático 4. liłlusofia da Educação, na PUC-SP entre os anos de 1948 e 1955.

1) origem belga, Leonardo Van Acker nasceu, em 16 de janeiro de $1: 49$, , na cidade de Bruges. Aos 25 anos fez-se doutor em Filosofia, I"1.1 Universidade de Louvain, onde era famoso o Instituto Superior 't. I Iilosofia (Escola São Tomás de Aquino) coordenado pelo Abade 1 1. iré Mercier, que influenciou as idéias defendidas por Van Acker. l.il Instituto situava-se dentro de um amplo movimento que visava ao 1-riscimento do tomismo em harmonia com o pensamento moderno. A . .u las, contra a tradição do latim, eram ministradas em francês, "para (tuito de demonstração da atualidade do tomismo".2

No ano de 1921, Leonardo Van Acker chegou ao Brasil com a uncumbência de substituir Carlos Sentroul na cátedra de Filosofia da 1.muldade São Bento, uma das faculdades constitutivas da PUC/SP, e P.ura onde se volta este artigo. Ao ser fundada a PUC-SP em 1946, I cunardo Van Acker fez parte do Conselho Técnico e Administrativo ‘.ı Faculdade de Filosofia de São Bento tendo pertencido ao Instituto Iirasileiro de Filosofia do qual foi membro-fundador. Responsabilizou“ por diversas cadeiras, nas várias unidades que constituíam a PUCSI? Na Faculdade Paulista de Direito, foi catedrático de Filosofia do 1)ırcito; na Faculdade de Filosofia Sedes Sapientiae, catedrático de lìlısofia, Lógica e Criteriologia; na Faculdade de Filosofia de São Bento, I itusofia Geral, Metafísica, Lógica, Introduçāo à Filosofia, História da Iilosofia Moderna, Filosofia Social e Filosofia da Educação, a partir ile 1948 (Cf. Granjo, 1999, p. 332-333).

Intelectual rigoroso com o seu trabalho e homem de vasta cultura tilosófica, Leonardo Van Acker foi considerado, em certos círculos, um dos maiores conhecedores da filosofia de sua época, embora tenha privilegiado os princípios da filosofia neotomista na formação dos estudantes, nos artigos publicados, nas palestras proferidas e nos inúmeros encontros de católicos dos quais participava ativamente.

Como defensor intransigente da Filosofia de São Tomás de Aquino, l.conardo Van Acker procurou manter uma postura próxima à dos seus mestres louvainenses, qual seja, a de busca de uma harmonia entre o tomismo e o pensamento moderno, daí sua abertura ao diálogo com as correntes modernas e contemporâneas da Filosofia. Tal abertura,

Armário da Faculdade Live de Filosofia e Letras de Săo Paulo, ano I, 1908 (Apud Casali, 1995, p. 94). 


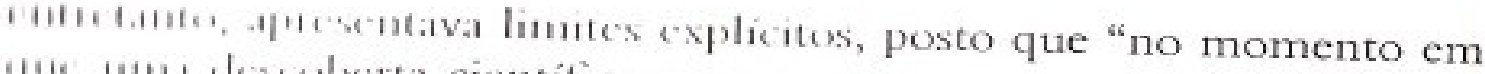
flit 1111.1 deswlerta cientílica nova e segura pusesse em cheque uma 14 '.t Infwofica partilhada por Santo Tomás ou Aristóteles, nós 11.114 111111.1mos uma tal tese, sem sombra de pena" (Sentroul, Apud ( 111 й, 19) $(8$, p. 75).

( ) l.to cra que, entre todas as correntes de pensamento, estava '111130 cin primeiro plano, a filosofia tomista. Segundo Antônio J. Svrturs (1997, p. 34), esta "é a forma mais perfeita e acabada do modo untalisico de pensar, no sentido que a metafísica assumiu na tradição "ulutral do Ocidente". Trata-se da retomada do pensamento de Aristóteles, devidamente adaptado aos princípios teológicos do cristianismo.

São Tomás de Aquino considerava que, se o aristotelismo era, de fito, uma doutrina racional, o aristotelismo cristão deveria ser possível, posto que a razão jamais poderia contradizer a verdade, do mesmo modo que a verdade racional nāo poderia contrariar a verdade revelada.

De acordo com Severino (1997, p. 36), a influência do pensamento tomista na cultura brasileira foi marcante. Essa hegemonia só começou a ser questionada com a chegada ao Brasil, na virada do século XIX, do Positivismo com seus pressupostos ligados ao cientificismo iluminista, "o que na educação se dará mediante o desenvolvimento da Escola Nova, sob a égide da ideologia liberal".

De fato, os pressupostos filosóficos do tomismo, defendidos com veemência por Leonardo Van Acker, encontraram, sobretudo nos anos de 1930, reação intensa por parte do grupo dos chamados pioneiros da educação nova. Durante esses anos e a primeira metade dos 40 , afirma Granjo (1999), a produção intelectual de Van Acker concentrou-se nas questôes referentes à educação brasileira, polemizando ativamente com esse grupo.

A crítica aos pressupostos filosóficos da Escola Nova e dos seus principais expoentes tanto no mundo afora (Rousseau, Dewey, Kilpatrick e outros, segundo Van Acker) quanto no Brasil (Anísio Ceixeira, Lourenço Filho, Fernando de Azevedo e outros) constituiu, pode-se dizer, a principal disputa, dentro do campo filosóficocducacional, no período em tela. Este fato é perceptível nos periódicos, uos congressos e encontros de inspiraçăo católica, nas publicações em livros, nos debates em torno da LDB de 1961 e através de um campo específico do conhecimento por onde essas questões, naturalmente, designguam: o campo do ensino. 
Isspecialmente na condição de professor catedrático da disciplina I 1 a iria e Filosofia da Educação na Faculdade de Filosofia e Letras de i... 13ento, Leonardo Van Acker impetrou a essa disciplina a sua marca i. likísofo neotomista. Mostrando-se aberto ao novo, nāo deixava de 1.. suas desconfianças quanto às novidades do mundo moderno, fut terindo, antes, a continuidade segura da tradiçāo.

\section{Os programas de Filosofia da Educação}

O projeto católico do qual Leonardo Van Acker era um expoente '11] œrtante, se consubstanciava na formação cristã das mentalidades a $1 \ldots 1$ de fazer frente às ameaças trazidas pelo laicismo e suas conseqüências - praiadas por todos os lugares. Mas, como lembra Cury (1988, p. 151), 'রu "não se conseguiria sem uma exata noção do que pensam os outros, ‘11 seja, os contrários a estas metas". Por isso, afirma o autor, os que "wio fora de suas fronteiras "devem ser conhecidos como conhecidas : uis posturas, ante o catolicismo." Para tanto, "os católicos deveriam "leixar as atitudes defensivas e partir para as ofensivas em torno de veículos " 'mo: jornais, rádios, bibliotecas, etc." (Ibid., p. 151).

Os programas construídos por Leonardo Van Acker, para direcionar " cnsino de Filosofia da Educação, pode-se dizer, tinham exatamente "ste sentido de espaço de aprendizagem da "exata noção do que pensam us outros" (Cury, 1988, p. 151), isto é, os seus contrários e de suas posturas frente aos princípios cristāos. Ao mesmo tempo, cles cram 1 m. espaço privilegiado de afirmaçāo apologética desses princípios.

Em geral, seus programas se concentravam em quatro assuntos: $1^{\circ}$ .lbordagem sobre a história da filosofia; $2^{\circ}$ - preocupação epistemológica cm explicitar o significado das expressö́cs: filosofin, ciêucia, educaçioo, filosofina da educaşāo, bem como das relaçôes que possam existir cutre esses termos; $3^{\circ}$ - referência aos valores e fins da cducaçāe; c, cm menor proporçāo $\left(4^{\circ}\right)$, a presença de temáticas de corte psicológices.

No primeiro caso, a História da Filosofia é traduzida pela proposição nos programas da Filosofia Antiga e Medieval e pela Filosofia Moderna. Quase não há referência à Filosofia Contemporînca. No primciro programa de Filosofia da Educaçāo, datado de 1948, Lconardo Van Acker não transpōe os limites da idade antiga c medicval c enfatiza temas como: o platonismo pedagógico - Sócrates, Platāo, os socráticos menores, o estoicismo e epicurismo; o néo-platonismo pedagógico: Plotino e Santo Agostinho; o peripatetismo pedagógico: Aristóteles e Tomás de Aquino. 
I:m 1951, o programa circunscreveu seus conteúdos a partir de duris cixus básicos que vão dos pré-socráticos a Santo Agostinho, a saber: studo do socratisho e platonismo educativo: Sócrates menores: cirenaicos, cínicos, ¿'stúcos, epicurismo, neo-platonismo, Plotino e Santo Agostinho.

A predominância da História da Filosofia nos programas de Filusofia da Educação de Leonardo Van Acker, sobretudo, da Filosofia Antiga e Medieval, em relação à Filosofia Moderna se deve a alguns fatores, tais como: a) à sua formação filosófica haurida nos anos que passou no Instituto Superior de Filosofia em Louvain onde se bacharelou, licenciou e doutorou em Filosofia e Letras, recebendo a influência dos mestres neotomistas Desiré Mercier e J. Maritain; b) a uma concepçāo de filosofia como síntese integral do saber humano, típica dos filósofos gregos; c) ao fato de que a filosofia medieval corporificada na patrística e na escolástica, tendo em Van Acker um herdeiro legítimo desta última - se nutre no pensamento grego, especialmente, cm Platão c Aristóteles; d) à condenação dos filósofos modernos pela Igreja Católica.

humanismo helênico fói, portanto, a fonte inspiradora de uma concepção filosófica que atravessou a prática de Leonardo Van Acker em função do sentido de unidade do saber e de concepção total da realidade que carrega consigo, tal como expressa abaixo:

A philosophia antiga teve o culto da unidade. Platão no Banquête recomenda a contemplação da Idéa do Bello Absoluto, princípio da vida verdadeiramente moral. A tradição christã, - desde os Padres da Egreja, inspirados sobretudo na metaphysica platônica; até aos Dontores medievaes, seguindo em maioria a esteira de Aristóteles - foi unânime em formar, de acôrdo com os requisitos da consciência moral e religiosa, comprehensiva concepção de philosophia. ${ }^{3}$

Paralela ao culto da unidade que caracterizou o humanismo helênico, estava a crítica desferida contra a falta de unidade característica da Filosofia Moderna. Para Van Acker (1926, p. 32), Descartes teve um papel-chave neste processo, posto que ele teria "inaugurado o rcgime de separação" entre os saberes ao conceder supremacia à razão e à dúvida,

'A citaçio ć de Lconardo Van Acker (1926, p. 32), bascando-se no filosofo D. Mercier. 
fumulumindo, com isso, para todo tipo de licenciosidade c anarquia pvil. un's na época moderna.

Inicrpretando Leonardo Van Acker, em sua crítica aos filósofos IIn-1. ins, Maria Helena B. Granjo (1999, p. 336) acrescenta que cla é Hevil. . . um fator relacionado à perda da perspectiva religiosa entre Bun : I,lisufos. É que os modernos, diz a autora,

não contentes em abandonar a tradição religiosa, teriam abandonado também a tradição filosófica e dado origem a uma forma de pensar não apenas individual, como individualista (...) tal individualismo, próprio da época, tinha reinado igualmente entre os cientistas.

1) f.u(u, a concepçāo de Filosofia de Leonardo Van Acker em tudo Viı ॥l. I I uma possibilidade de escalada para as dimensōes do "supraHhavil" " para o "extrafenomenal", para usar uma expressão de Inolulile, Miranda Santos (1935, p. 82), um nome sempre presente htre $\ldots$ liksofos da educação adeptos do tomismo. Santos dizia, Itleumlı, i influência positivista, que a filosofia jamais deveria ser uma

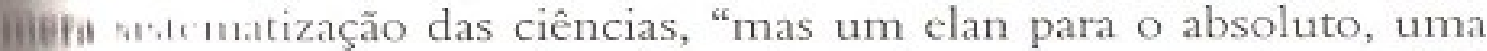
(1) alidiule" (Ibid., p. 82).

Cimipre também relembrar que, desde o século XIX, a Igrcja holin a livvia publicado uma série de encíclicas onde advogava uma Hen ، «trária aos pressupostos do modernismo que tantos Hilnatume the trouxera. Corroborando com estas críticas, Pe. Leonel | Bliein... as rupturas ocasionadas na cultura pelos pensadores que h6afam un mundo em que vivemos o tumulto das idćias loucas (...)

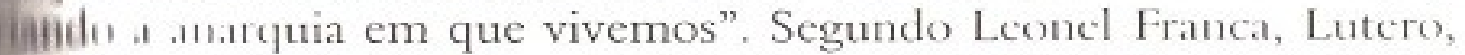
Hhenros. Kant, Comte, Nietzsche e Marx foram os maiores ponańve pela "crise do mundo moderno". O abandomo da revelação Ill eumsisturia na razão suprema dessa crise. ${ }^{4}$

Eonturlu, Lconardo Van Acker, embora um crítico da Filosofia Herm, 11.1 usou isso como estratégia de apagamento das temáticas

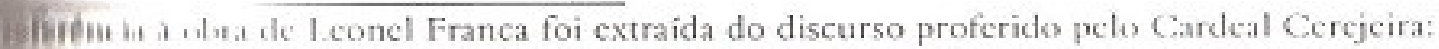

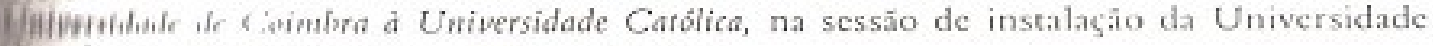
Illet de vin 1'auls (he: Arais, 1946, p. 68-69). 
I11.191.1s do periodo. Aliás, uma característica encontrável nos seus "Altus a a cipacidade de, ao tratar um determinado assunto, primeiro desteve-lo $\mathrm{cm}$ detalhes para, somente depois, lançar-lhe as devidas 'rilcias. É preciso frisar, todavia, que a presença nos programas de Filessofia da Educação de Van Acker, de temáticas (ou filósofos) pertencentes à época moderna, provavelmente, significou uma uportunidade para elc exercer seu potencial agudo de crítica e, ao mesmo tompo, uma possibilidade de enaltecimento da filosofia tomista,
considerada a mais perfeita.

Assim, no programa de 1948, e em outros, pode-se encontrar os scguintes temas e autores: o racionalismo pedagógico de inspiração cartesiana; o empirismo e associacionismo: Locke, Bain, Herbart; o individualismo pedagógico: Ronsseau, o socialismo pedagógico.

Pelo menos em relação a Rousseau, Leonardo Van Acker, nos seus textos, foi impiedoso quanto à concepção que tinha da infầcia, do papel do preceptor e da existência de incompatibilidade entre a natureza infantil e a sociedade. Fundamentalmente, Leonardo Van Acker (1959, p. 599) não admitia, em Rousseau, a idéia de que, entre as necessidades que a criança na idade escolar precisava conhecer, não figurava "a de ser instruído, nem mesmo a de ser informado..."

Contra isso afirmava que,

não é sem opontunidade lembrar essas idéias em face da pedagogia 'Nova', cujo espirito muitas vezes tende para certa instrução que é a negașão do ensino e requer discípulos que já não sejam proprianente alunos. E tal é a tendência de todos aqueles que exageram o alcance dos métodos activos (Ibid., p. 559).

Assim, se Leonardo Van Acker dava especial atenção à Filosofia Moderna com o intuito de, sobre ela, descarregar toda a sua crítica que, aliás, era a mesma da Igreja Católica. Isto talvez explique a quase ausência cm seus programas de ensino da Filosofia Contemporânea. É que para cle, de acordo com Granjo (1999, p. 336), havia uma "superioridade incgível da filosofia contemporânea em relação à sua congênere moderna", porquanto ela "representava o retorno à reflexão metafísica, e nāo seria avessia à tradiçāo filosófica e mesmo religiosa". Assim sendo, a Filosofia Contcmporânea, pela sua afinidade com a Metafísica, não representava qutalyuer ameaça a ser combatida que justificasse a sua inserção nos proṇ: anis.s de Filosofia da Educação, trabalhados em sala de aula. 
( ontudo, havia em seu interior uma corrente considerada uma Phin, .14, uma quase heresia e que, portanto, pelo perigo que representava

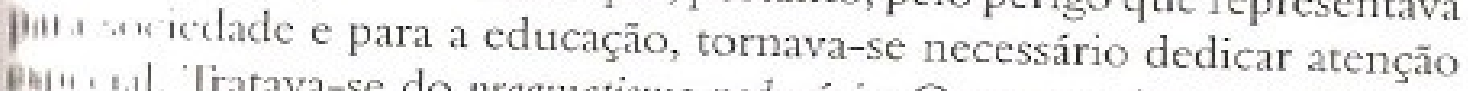
Paj" + . .1. Tratava-se do pragmatismo pedagógico. O pragmatismo de Dewey, Eiii it unstituindo no principal objeto de crítica dos católicos, desde a He ...1. ale 30, ocupou espaço deveras ampliado na disciplina Filosofia

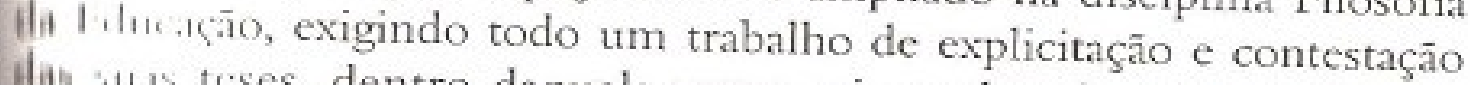
Ham a 11.15 teses, dentro daquela perspectiva colocada por Jamil Cury (10mi. 1) 151) de se conhecer as posturas daqueles que estăo fora das Anu+11.as católicas.

I.+11ardo Van Acker (1931, p. 81) referia-se ao filósofo norte Imin .114, como sendo "o maior e mais authêntico dos fhilosophos da Jibul. unva," diferenciando-o de posturas absolutamente condenáveis $0111 \ldots$ a de Rousseau. Contudo, não admitia a doutrina de que se mbiatuva Dewey em funçāo de ser nâo só "naturalista, mas sobretudo Diatrit.11st:" (Van Acker, 1957, p. 408).

Se pur materialismo entende-se a "redutibilidade total do real à niatru. 1 u a forças inteiramente sujeitas às condições da matéria" G14lys: 1, 1987, p. 262) e, portanto, a negação ao homem de sua dimensão

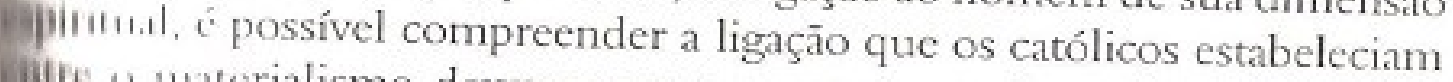
Iitie w inaterialismo deweyano e a conseqüente desordem que a falta 19 As criaria na sociedade ao abrir caminho para a implantaçĩo do

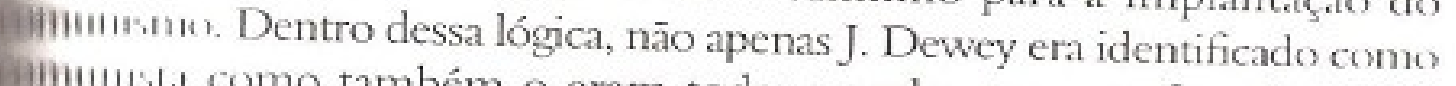
Jimini li. como também o eram todos aqueles que, confessadamentc, Hefir.min as pressupostos de sua filosofia como, por exemplo, Anísio

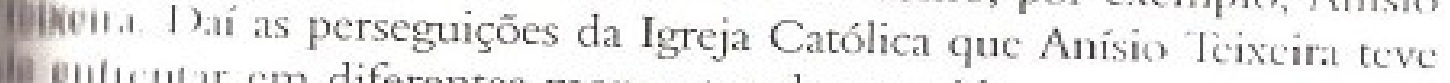
Eilicillar cm diferentes momentos de sua vida.

(1) Ituturalismo pedagógico já havia sido condenado pelo papa Pio 60mu lalso e perigoso, desde 1929, na Encíclica Divini Illius Mapistri [unal, w! !usdo Casali (1995, p. 107), "forneceu o paradigma doutrinário nian clalurado dentro do qual a Igreja no Brasil passou a conformar iaj ilin tativas no campo educacional". Os filósofós da cducaçî́o de iipiras.... tomista criticavam o naturalismo pedagógico em função dele f reilu/kds a Filosofia à ciência, a Psicologia a uma ciência experinental finuluncutc, pela ignorância quanto aos aspectos sobrenaturais do scr

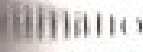

Pulv se também relacionar a crítica de Leonardo Van Acker a John Dewey n. protestantismo deste. Segundo Cury (1988, p. 140-141), para batolus 
as matrizes do pensamento reformador são provindas de países protestantes. Isto é, suas teorias näo se identificam com a "alma católica" do povo brasileiro e nem com a personalidade histórica do mundo sulamericano.

Assim, continua o autor:

Se o protestantismo aceita o sobrenatural, sen libertarismo contra a autoridade interpretativa da Igreja, sua separaçāo entre fé e razāo criaram condições para o advento de um naturalismo filosófico e pedagógico e de um liberalismo político individualista e ganancioso (Ibid., p. 141).

A crítica de Leonardo Van Acker (1957, p. 412-413) a J. Dewey é ainda acrescida de um agravante: o fato de Dewey ter abandonado até mesmo a religião em que fora educado (o protestantismo) para cultuar, em seu lugar, "uma religião puramente natural e humanitária...", preferindo, com isso, "a fé na ciência e na democracia." Em outras palavras, se o protestantismo, por si só, representava para a Igreja Católica uma ameaça, o abandono deste pelo filósofo pragmatista representava algo tão ou mais nocivo, posto que significava, implicitamente, sua adesão ao ateísmo. Para Leonardo Van Acker, Dewey, ao se voltar à ciência e à democracia, transformadas em nova religiăo, se tornou um sectário para com a religiāo cristā e seu ensino nas escolas públicas dos Estados Unidos.

Outras temáticas recorrentes no programa de Filosofia da Educação ensinados por Leonardo Van Acker eram: a definiçāo de filosofia; filosofia e ciências; filosofia e cosmovisão; definiçōes da educação.

Com relação à sua concepção de filosofia, cumpre ressaltar o nexo que estabelecia entre ela e a atividade de ensinar. Para ele, "a philosophia ć um ensino e mesmo antes de tudo um ensino". E embora reconhecesse que como profissão ela "dá poucas riquezas porque foi dito que a metaphysica não paga o homem", Van Acker $(1929$, p. 22) ressaltava que cra "incalculável" a "influência social e prática da Filosofia".

De fato, Leonardo Van Acker se movia no mesmo terreno da Igreja Católica, na sua convicção de que, fundamentalmente, pelo ensino se pulcria conformar as mentalidades a seus ideais. Não foi insignificante, aliás, a influência exercida por ele sobre seus inúmeros alunos os quais, segundo Granjo (1999, p. 337), "provavelmente multiplicaram suas idcias, na funçāo docente, na magistratura, ou na carreira política". 
No que se refere à filosofia e à ciência, a relação que existia, scgundo V.u Acker, era de subordinação desta em relação àquela. Nas suas palavras:

... a ciência depende indiretamente (relativamente) da filosofia, porque esta funda o direito dos primeiros princípios conhecidos $e$ aceitos espontaneamente pelo senso commm. A filosofia rege ainda as ciências, indicando a cada uma delas o sen lugar próprio (1922, p. 119).

A concepçāo de ciência submetida à filosofia tipifica uma แu- ntalidade arraigada ao pensamento escolástico, em que as dimensões 1. Lịinsas, metafísicas e científicas não estavam dissociadas e na qual a I limsofia reinava soberana. Nesse sentido, a Idade Média simbolizava f $, 11,1$ Leonardo Van Acker, o ideal a ser restaurado. No seu entender, a Ansuciação entre os saberes, cxistente a partir do século XIX, se -videnciava pela supremacia que tiveram as ciências naturais e 11. temáticas em relação à filosofia e à metafísica, originando o untificismo, isto é, a crença de que a ciência por si só solucionaria os 111.1les da humanidade. A restauração do primado do pensamento l.lısófico, no conjunto dos saberes e no resgate do papel da teologia - um orientadora geral de todas as ciências, fazia parte do movimento uncrnacional de renascimento do catolicismo, segundo o qual a Iniversidade de Louvain era modelo.

Para Leonardo Van Acker (1930, p. 16), a crescente especializaçăo du conhecimento em diferenciadas esferas do saber e a sua subordinação .t tirania positivista teriam violado a hierarquia natural entre as ciências warretando, com isso, a perda da integralidade científica característica 4o regime universitário medieval. Nessa acepção, criticava os excessos ha mentalidade positivista para quem a filosofia deveria subordinar-se is ciências. Contrariamente, cabia à filosofia - como "scicncia da essência c existência das cousas" - o papel supremo de estabelecer o lugar próprio de cada ciência.

Desta perspectiva ampla de filosofia decorria a sua concepção de filosofia da educaçāo, a qual deveria dar a última palavra sobre a ciência pedagógica. Paradoxalmente, embora necessária essa relação entre filosofia e pedagogia, esta estava subordinada àquela corroborando com a concepçāo de Van Acker de que "a parte só se entende no todo e de que, sem a compreensāo geral do sentido da filosofia, qualquer conhecimento específico carece de sentido" (Granjo, 1999, p. 337). 
Assim, salvaguardando o papel essencial que tinha a teologia, o culuc lilusśfico, por excelência, era o único capaz de, em funçẫo de sua vancicio de saber total, ditar as regras para as demais ciências. Do mesmo шurke, seguindo a linha silogística característica do seu raciocínio, cabia i. Lilusotia da Educação, em relação às demais ciências educacionais, uni: função tāo ampla quanto a da filosofia, isto é, a de determinar os fins da codecaçión.

A questāo dos valores e dos fins da edncaçāo constituía outra problemática central nos programas de Filosofia da Educação, de Leonardo Van Acker. Segundo ele,

... intelectualismo exagerado na pedagogia moderna e o consequiente desleixo na formação do caráter, salientado pelos nossor educadores, são afinal resultados do preconceito de que a pedagogia é apenas sciência de observação e experiência filiada à psicologia sem nexo com a moral (Van Acker, 1930, p. 21).

Leonardo Van Acker (1930, p. 17) não tinha dúvidas "de que formação educativa" era "objeto de certa sciência ou técnica". Para ele isto "é quanto basta para definirmos a filosofia pedagógica: a crítica do postulados da técnica ou sciência pedagógica" (Ibid., p. 17), para além dos modernos reducionismos metodológicos dessas teorias. Embori reconhecesse os progressos trazidos pelo movimento pedagógico moderno, Leonardo Van Acker reiterava que as técnicas, para scren! eficazes, năo poderiam estar dissociadas de um ideal educativo. Pafi cle, a definição desse ideal constituía a tarefa própria da filosofil pedagógica ou da Filosofia da Educação.

Da crença - objeto de crítica dos católicos aos filósofos moderno - de que "a pedagogia é apenas sciência de observação e experiêneii filiada à psicologia e sem nexo com a moral" (Van Acker, 1930, p. 21) decorria a necessidade imperativa da filosofia pedagógica pois, no seit dizer: "se queremos a última palavra da razão humana sobre o valer dos postulados pedagógicos e da própria sciência educativa, havemo: de recorrer à filosofia da educaçăo" (Ibid., p. 21-22) porquanto, cabe cla a tarefa de manter um ideal elevado na educação. ${ }^{5}$

- A expuessão filosofia pedagogica é utilizada cm texto do mesmo nome por Lconardo 
A Filosofia da Educação deveria ser praticada ainda para evitar que o Inu (14 40, p. 22) destacou "o plano geral da filosofia educativa". Segundo ele:

Os problemas maiores são os da essência, do fin e da existência da educação, bem como da essência e existência da própria sciência pedagógica. Tais questöes podem ser tratadas por am exame positivo e lógico, precedido dum estudo histórico e crítico das várias teorias modernas de filosofia pedagógica.

Este argumento, provavelmente, explicita a forma como Leonardo V.ı Acker trabalhava a Filosofia da Educação. Centrava sua atenção na I Iıstória da Filosofia para dela derivar consequiências para a educação. l.1 procedimento teve longa duração na forma de conceber a disciplina.

Finalmente, cumpre salientar a presença (ainda que em menor .tance) de temáticas de corte psicológico nos programas de Filosofia da lislucação de Leonardo Van Acker, a saber: os fatos educacionais básicos: "Iprendizagem e ensino; conceituaçāo de aprendizagem; conceituação de ensino; o chlucando, sua natureza e fins psicológicos imedialos: o comportamento humano, a munivaşāo do comportamento humano, leis e princípios da aprendizagem humana. Isstas temáticas, provavelmente, nāo guardam relaçōes com a influência ularcante que teve a Psicologia na conformação do campo educacional. Antes, podem estar ligadas à intrínseca relação que, desde os gregos, rxistia entre Filosofia e Psicologia, em que esta, como estudo da alma, 'Ta um campo de conhecimento tratado pelos filósofos.

A simbiose entre essas áreas só foi rompida, no século XIX, com o advento das ciências experimentais que, influenciadas pelo Positivismo, cxcluíram a metafísica assim como todo conhecimcnto que Iranscendesse o fenômeno sensível do âmbito da Psicologia Filosófica. Foi somente a partir desse século que a Psicologia se tornou uma ciência scparada da Filosofia.

Na realidade, a separaçāo da Psicologia da Filosofia teve implicaçóes nāo apenas de ordem epistemológica. Ao se separar da Filosofia, a Psicologia, no intuito de constituir-se em um campo próprio de saber, apoderou-se de um objeto que não cra seu, mas, historicamente, da Filosofia, qual seja, a alma humana, sede das cmoçōes, vontades e desejos humanos. Desse modo, influenciada pelo positivismo, a Psicologia passou a assumir a responsabilidade de medir e controlar o comportamento humano, apoderando-se, portanto, não apenas de um 


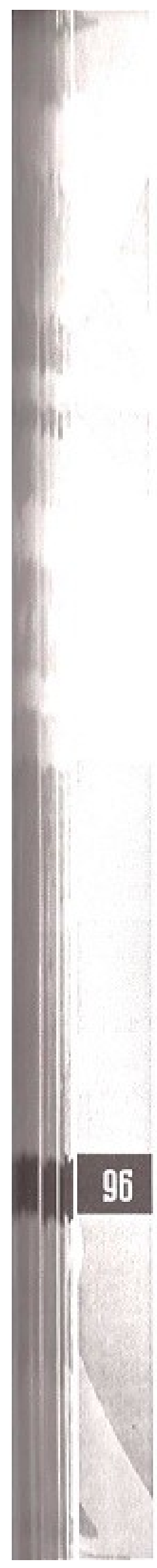

ulucto alsstrato de conhecimento (a alma), mas, fundamentalmente, 4h. um objeto concreto de controle sobre homens e mulheres, há muito de domínio filosófico, leia-se, religioso.

\section{Filosofia da Educação: bibliografia e eventos na década de 40 e 50}

Do ponto de vista da bibliografia dos programas de Filosofia di İducação, embora não haja explicitação do que era indicado para lcituri $\mathrm{cm}$ sala de aula, posto que isso parece nâo constituir uma exigência nesse período, ao final do programa de 1961 - o último encontrado sob a regência de Leonardo Van Acker - ele escreveu: "o programa inspira principalmente no livro de W. F. Cunnigham: The Pivotal Problen! of Education; Na Introdution to the Christian Philosophy of Education Subsidiariamente serão aproveitados os livros de Redden e Ryan, Alve: Siqueira e De Hovre".

De acordo com Leonardo Van Acker (1969, p. 17), a obra Filosofit Pedagógica (1924) de De Hovre teve enorme influência nos "tratador pedagógico-filosóficos mais sistemáticos" escritos por Antônio Alve de Siqueira (Filosofia da Educação de 1942) ou a Catholic Philosophy of Education de J.D Redden e F. A Ryan, (1942). Foram esses filósofos di educação, todos católicos, que deram a ler a realidade educacional de período e que, provavelmente, subsidiaram os programas da disciplini Filosofia da Educaçāo analisados.

No que concerne ao mercado editorial, as décadas de $40 \mathrm{c} 50$ especialmente, ofertaram na esfera da Filosofia da Educação, uma gam significativa de manuais, cujos autores, na sua quase totalidade, crani homens provenientes de uma formação religiosa de base católica Acrescente-se também o papel privilegiado que teve a Revista $A$ Orden na publicação de artigos filosófico-educacionais de inspiração cristú do Boletin da Associação dos Professores Católicos (APC).

\footnotetext{
"Eis o exemplo de alguns livros de Filosofia da Educação que o mercado editorial ofertou periodo em tela: Rui de Aires Belo. Filosofia e Pedagógica: Para as cadeinas de carso pedagúglco insrituto de cducaçāo do Brasil. Séric Didática do Brasil. 1956; Frans De Hovrc. Pedagogos y pedege Whl ratolicismo. Madrid. 1948; Frans De Hovre. Ensaio de filosofia pedagogica. Série Atualliti Pedagósicas, SP: Nacional. 1969; Alecu Amoroso Lima. Humanismo pedagógico: estudos filosofia da cducaçāo. In: Coleçāo Presença. vol. XI. RJ: Stella editora. 1944; Jacques Maritit Ḱrunos da edną̧áo. Tr.: Inês Fortes de Oliveira. RJ: Agir. 1947; John D. Redden e Franeil Ry:un. Fïlosofia da Edncasáo. $2^{3}$ ed. RJ: Agir. 1961; Tcobaldo Miranda Santos. Filosofia da editedil ps ytamies problemas da pedagogia moderna RJ: Bofifoni. 1942; Tcobaldo Miranda Santos. Noplle

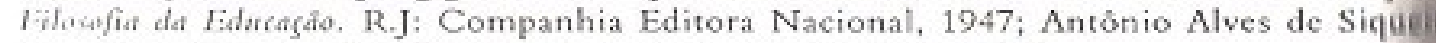

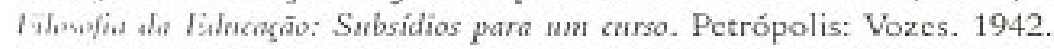


$\Lambda$ proliferação dessa produção pode estar relacionada ao fato dc 'I" a I Isrcja Católica nāo tendo conseguido atingir o controle exclusivo 4. 'A clucação superior no Brasil com vistas a formaçāo das elites, I'+1 isava, contudo, combater seus inimigos e enaltecer seus ideais não "M nals a partir da universidade católica, isto é, das disciplinas e dos l'urramas de ensino, como também de toda uma produção teórica Heilicada a esses objetivos. Nessa direção, foram abundantes as pulblicações em livros e revistas que circularam, sobretudo, durante a " lru ula de 40 e 50 , visando obter adesão do professorado.

De fato, ao falar sobre os espaços de legitimação e circulaçāo da 1. xduçāo filosófico-educacional de inspiraçāo católica, é preciso remeter ... pipel privilegiado que teve a revista A Orden. A despeito da existência 1. "sutros veículos, como a Revista Brasileira de Pedagogia (RBP) e a Revista Ihtwileira de Estudos Pedagógicos (RBEP) na publicaçāo de artigos da área, - us interior de A Ordem que se pode obter, de modo claro, uma visão 'ง que foi a Filosofia da Educação, quando da sua institucionalização na unversidade católica. ${ }^{7}$

Em todo caso, cumpre registrar que esses veículos de divulgação, - -mbora abarcando a problemática filosófico-educacional do período, 11.16 se constituíam como veículos próprios da área, posto que abrigavam issuntos de variados âmbitos do conhecimento.

\section{Consideraçōes finais}

Tendo surgido como disciplina em meio à suposta crise do mundo unsderno, a Filosofia da Educação foi compreendida pelos intelectuais Iute fizeram parte da sua história, no período de 1940 a 1960, como 1 um saber que tinha por função essencial contribuir para a construção de $111 n$ ideal elevado para a educaçāo, definindo guais os fins c os valores "fue valiam a pena ser transmitidos. Esse ideal, em geral, for definido a partir de algumas autoridades, tais como Sä́ Timíís de Aquino ou o prapa Pio X.

A primeira geração de professores de Filusofia da Educação disseminou suas idéias em diversas revistas da ćpoca ( $A$ Ordem, Revista

\footnotetext{
Para uma análise da RBP, vide a disscrtaçăo de Sgarbi (1\%)7), l'ara tma análise das principais concepçōes de filosofia da educação veiculadas pela RBE:P, vide Saviani (1984, p, 273-290).
} 


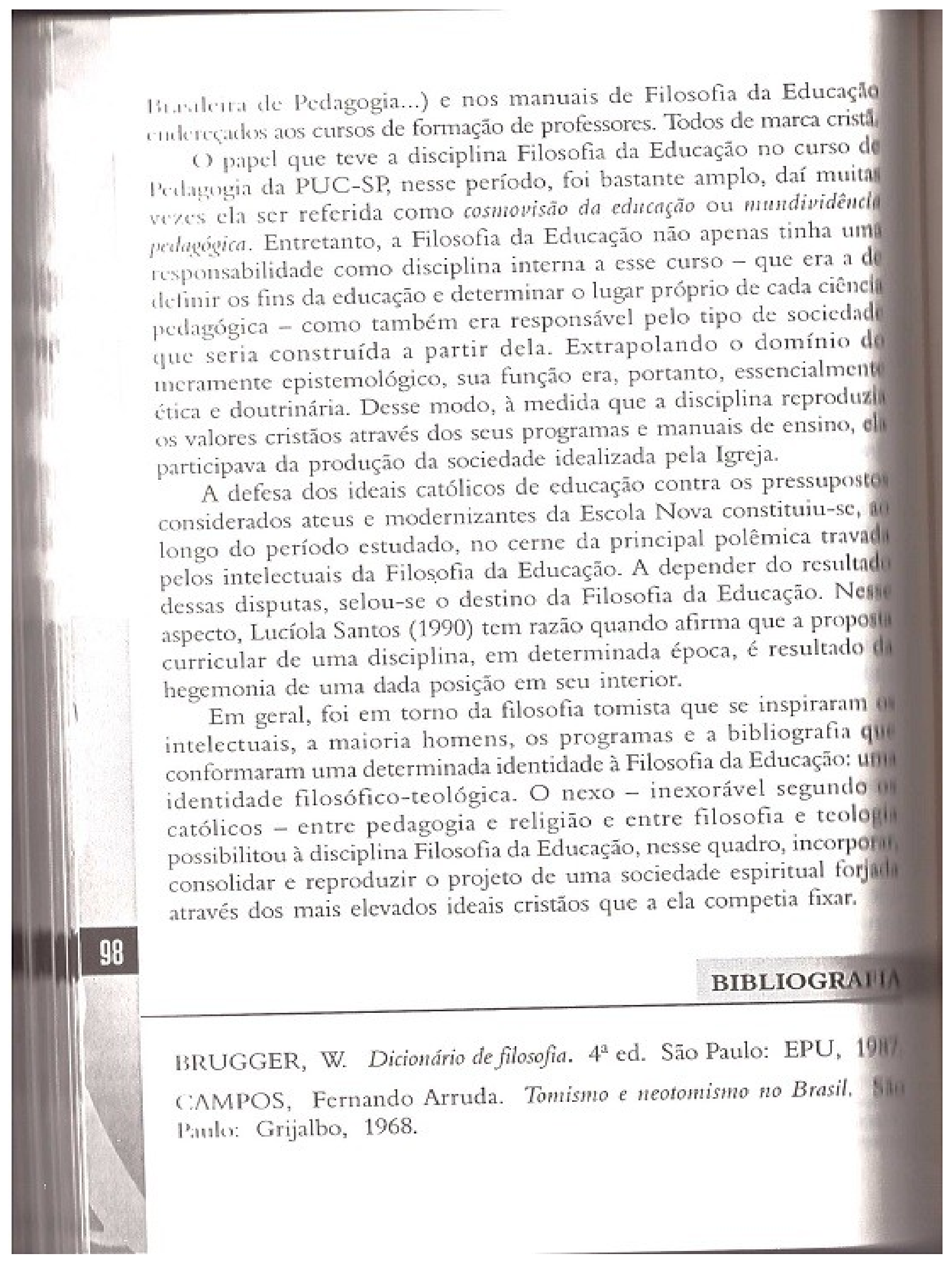


( A AII, Alípio. Elite intelectual e restauraģão da Igreja. Petrópolis: Vozes, 1\%

( 1 IRY. Carlos Roberto J. Ideologia e educação brasileira: católicos e liberais, 1" +1 S.ü Paulo: Cortez-Autores Associados, 1988.

(ileANJ(), Maria Helena B.; VAN ACKER, Leonardo. In: FÁVERO, Min 1. de Lourdes de A.: BRITTO, Jader de M. (orgs.). Dicionários de Hhiuwhurs no Brasil: da colônia aos dias atuais. Rio de Janeiro: Editora da UIlर. 14x9, p. 333-338.

OI IVI:IRA, J. H. Barros de. Filosofia, psicanálise e educação. Coimbra: livi.11., Nlinedina, 1997.

Pll lel / : (I, Antônio Flávio de Oliveira; SOUZA, Beatriz Muniz de; IAMArio, Cândido Procópio Ferreira de. Igrcja Católica: 1945-1970. hil I A1 IsIO, Boris (org.). História geral da civilizaçāo brasileira. tomo III + It isil republicano. $4^{\circ}$ volume: economia e cultura (1930-1964). Inl S.m Paulo: Difel, 1990, p. 345-380.

UUt ' SP' - Pontifícia Universidade Católica de São Paulo. Estatutos. (ii) Alusi Sino Paulo: Ave Maria Ltda, 1946, p. 201-205.

IOSA, Maria da G. de. A história da educaşāo através dos textos. $19^{\mathrm{a}} \mathrm{ed}$ fo l'muls; Cultrix, 1993.

AN I is, Lucíola. L de C. P. História das disciplinas escolares:

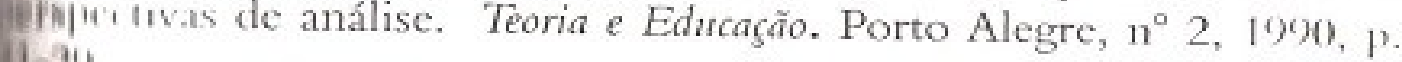
$122^{4}$

ANI' «s, Reobaldo Miranda. Depoimento (saudaç̃o feita duraute o Hefs cucarístico de Campos). A Ordem. Rio de Janciro, ane XV, 1) XIV. jul./dez., 1935 , p. 80-86.

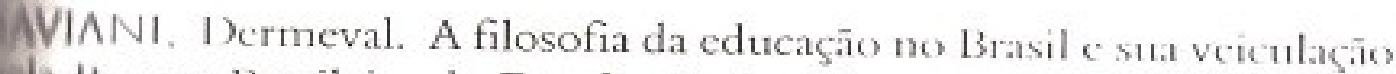
1h It'vesta Brasileira de Estudos Pedagógicos. RBI:P, Brasilia, maics/

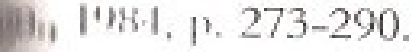

IVEIRIN(), Antônio J. A filosofia contenporânca no Brasil; conhecimemo, hilina r culucurcão. Petrópolis: Vozes, 1997.

AlıII. Antônio Donizetti. Igreja, edncação e modernidade na década de Pandumorismo católico. Dissertação de mestrado, Prograna de Hẹça: I listória e Filosofia da Educação, PUC-SP, 1947. 
VAN AC:KER, Lconardo. Introdução à philosophia: resumo destinado aos "Munos. Sĩo Paulo: Agrasso \& Pinheiro, 1922.

Lição inaugural pelo Dr. Leonardo Van Acker. In: Anuário do (In) letino de 1925. Faculdade de Filosofia e Letras de São Paulo. São I'anlo: Typographia Brasil de Rothschild, 1926, p. 25-49.

. Filosofia pedagógica. A Ordem. Rio de Janeiro, ano X, no 8/10 1) $3($ ), p. 12-23.

- Santo Tomaz de Aquino e a Escola Nova. A Ordem. Rio de Janciro, no 19,1931 , p. 139-145.

. O naturalismo de John Dewey. Revista Brasileira de Filosofia São Paulo: Instituto Brasileiro de Filosofia, 1957, p. 408-419.

- A Essência genuína da Escola Nova. Revista Brasileira de Filosofía São Paulo, vol. IX, fasc. 4, 1959, p. 595-605.

. Frans De Hovre: O Homem e a obra. In: HOVRE, Frans de Ensaio de filosofia pedagógica: Tr.: Luiz Damasco Penna \& J. B. Damasco Penna. São Paulo: Editora Nacional, 1969, p. XIII a XX.

Arttigo recebido no dia 16 de janeiro de 2005 e aprovado no dia 28 de abril de 2005. 